\title{
Prediction of stiffness and stresses in Z-fibre reinforced composite laminates
}

\author{
M. Grassi, X. Zhang*, and M. Meo \\ College of Aeronautics, Cranfield University, Bedford MK43 0AL, UK \\ (Received 14 November 2001; revised 9 September 2002; accepted 19 September 2002)
}

\begin{abstract}
The mechanical properties of z-pinned composite laminates were examined numerically. Finite element calculations have been performed to understand how the through-thickness reinforcement modifies the engineering elastic constants and local stress distributions. Solutions were found for four basic laminate stacking sequences, all having two percent volume fraction of z-fibres. For the stiffness analysis, a micromechanical finite element model was employed that was based on the actual geometric configuration of a z-pinned composite unit cell. The numerical results agreed very well with some published solutions. It showed that by adding two percent volume fraction of z-fibres, the through-thickness Young's modulus was increased by 22-35 percent. The reductions in the in-plane moduli were contained within 7-10 percent. The stress analysis showed that interlaminar stress distributions near a laminate free edge were significantly affected when z-fibres were placed within a characteristic distance of one z-fibre diameter from the free edge. Local z-fibres carried significant amount of interlaminar normal and shear stresses.
\end{abstract}

Keywords: Z-fibre; 3-Dimentional reinforcement; mechanical properties; stress concentration; finite element analysis (FEA).

\section{Introduction}

The notorious interlaminar weakness of laminated composites can be overcome by using fibrous reinforcement in the thickness direction, also known as the z-direction. Established processes such as industrial stitching and z-pinning offer economic means of achieving increased interlaminar fracture toughness [1-2]. This paper deals with z-pinned composites, which is defined as composite laminates with up to five per cent volume fraction of the z-fibres or z-pins. These zpins can be made of steel, titanium, glass, Kevlar, and carbon fibres depending on application [3]. This new 3D composite offers significant improvement in impact resistance, compressionafter-impact (CAI) strength, and the ultimate strength of stiffener pull-off [3-7]. It can be fabricated with small changes to the conventional cure cycles by using the Z-Fiber ${ }^{\mathrm{TM} *}$ technique, which allows composite designers to utilize the advantages of the well-established manufacturing approaches and yet to obtain three dimensional properties where needed [8-9].

The z-pinning process will affect laminate's stiffness properties and hence the global elastic response of z-pinned composite. Therefore, crucial to the development of the technology is to

\footnotetext{
* Corresponding author: Email: xiang.zhang@cranfield.ac.uk (X. Zhang). Tel No. 01234 754621. Fax No. 01234758203

${ }^{*}$ Z-fiber $^{\mathrm{TM}}$ is a registered trademark of Aztex Inc., Waltham, MA, USA.
}

obtain a better understanding of the mechanism and mechanics of z-pinned composites. Evaluating the engineering stiffness constants and examining the stress distribution around a z-fibre could be a first step towards the development of a design tool for predicting damage initiation and damage propagation in z-pinned composites.

For conventional laminated composites, there are two approaches to obtain the stiffness properties, i.e. macro-mechanical and micro-mechanical methods. The former uses experimental data from standard coupon specimens to build a set of material constitutive equations that results in engineering elastic constants. This approach treats a composite as homogenous orthotropic continuum, which may yield a useful design tool. However, to obtain an in-depth understanding of the material behaviour and accurate mechanical properties an alternative method is necessary. The micro-mechanical approach does not assume homogeneity, but defines the micro-structural details and uses the known material properties specific to both fibre and matrix to determine the overall behaviour of the composite material [1012]. Assuming that both the material structures and the mechanical response are periodical, composites can be modelled by a representative volume element (RVE) or a unit-cell (UC). A unit cell is the smallest region in a periodic material structure. This technique can also model more complicated textile composites, such as woven fabrics [12]. 
The unit cell approach has also been employed for modelling z-pinned laminates [13-14]. Lin \& Chan [13] used an analytical unit cell model that was based on the classical laminate theory, i.e. the rule of mixtures, by transferring the z-fibre stiffness onto the laminate plane and superimposing z-fibre stiffness to the in-plane laminate stiffness. While this approach is applicable to simple laminates, it is oversimplistic for z-pinned composites since it does not consider the interactions between the z-fibre and the surrounding resin zone (see Fig. 1a). The numerical or finite element (FE) unit cell model on the other hand takes account of the important micro-structural details, such as the pure resin region and the misaligned in-plane fibre region, both of which can influence the stiffness values. Dickinson et al [14] made a detailed FE unit cell model and performed an extensive parametric study of the z-pinned laminates in order to obtain the engineering elastic constants. He examined the effects of z-fibre material, volume fraction and insertion angle, and also the influence of the misaligned fibre region around the z-pins and the resin-rich pocket. However, a detailed stress analysis appears to have been omitted, which would help to understand the stiffness variations due to the presence of z-pins.

It is also important to examine the stress changes due to the insertion of $\mathrm{z}$-fibres, so that stressbased failure criteria may be applied for predicting damage initiation at stress raisers, e.g. at laminate free edges and open-hole edges. The stress state in a laminate is basically twodimensional, but in the presence of transverse loads (such as impact load) or geometrical discontinuities (such as free edges, open holes, and ply-drops) it becomes essentially threedimensional with very high interlaminar stress components [15]. Since the characteristic dimension of the z-fibre induced stress field is less than an individual ply thickness, z-fibre effect on stress components has been analysed at micro-mechanical scales [16-17]. Barrett [16] made a detailed FE study on a cracked z-pinned laminate. The work concentrated on the crack-tip stresses and the effect of z-fibres on interlaminar (Mode I) crack growth; the in-plane fibre waviness and the resin pools around $\mathrm{z}$-fibres were not included in the FE model. It was found that an intact $\mathrm{z}$-fibre could reduce the three principle stresses by $67-76 \%$ when the $\mathrm{z}$-fibre was placed in the immediate vicinity of the stress concentration zone. This result implies that crack propagation rate will be significantly reduced due to local intact z-fibres.

The objective of this work was to evaluate the effect of z-pinning on engineering elastic constants and on local stress distributions near a z-fibre. The laminates used in the study had $2 \%$ volume fraction of $\mathrm{z}$-fibres, which is the typical density used in many structural tests [18]. The work was carried out using a finite element unit cell model for stiffness analysis and a more detailed micro-scale 3D FE model for interlaminar stress analysis. The unit cell model for stiffness evaluation was similar to the numerical model devised by Dickinson et al [14]. The results presented in this paper were calculated in the linear elastic field and the curing stresses were not taken into account.

\section{Finite element models}

\subsection{Unit cell model for engineering elastic} constants

Fig.1 (a) is a microscopic photograph of a unidirectional (UD) laminate with a single z-fibre showing the distinct microstructures of the pure resin pocket and the misaligned in-plane fibres surrounding the z-fibre. In this study a 3D finite element unit-cell model, Fig. 1 (b), was used to model the microstructure of the unit cell. This micro-mechanical model consisted of 20-noded hexahedral elements. Different geometric shapes were used to mesh different regions within the unit cell following the star-pattern approach [14] to maintain mesh compatibility across the interface between the plies of different orientations. The NASTRAN software package was employed to perform the FE analysis. Four basic laminate stacking sequences were studied, i.e. unidirectional $[0]_{4}$, cross-ply $[0,90]_{s}$, angleply $[ \pm 45]_{s}$, and quasi-isotropic $[+45,90,-45,0]_{s}$. The composite laminate used in this computational example was made of the AS4/3501-6 carbon/epoxy pre-preg, and the zfibre pins were made of impregnated carbon tows (T300/9310) with axial Young's modulus of 144 GPa. The basic material properties inputted in the FE model were taken from references $[11,14]$ as given in Table 1 in order to validate the results against published data.

It should be noted that the z-fibre diameter used in the present work was $0.28 \mathrm{~mm}$, but in reference [14] two z-fibre diameters, 0.254 and $0.635 \mathrm{~mm}$, were used. According to the literature, typical range of z-fibre diameter is between $0.15 \mathrm{~mm}$ and $1 \mathrm{~mm}$ depending on different applications $[3,9]$. However, since the main variables of the model, 
i.e. the size of the resin pocket inclusion and deviated fibre region, were kept as the function of z-fibre diameter, the relative z-fibre densities in the two computational models were the same. Therefore, a direct comparison with [14] could be made. The region of intact lamina was not an issue for this model; therefore each single lamina was modelled as a homogeneous threedimensional orthotropic continuum with principal axes oriented in the local reference frames without the distinct representation of the fibres and matrix.

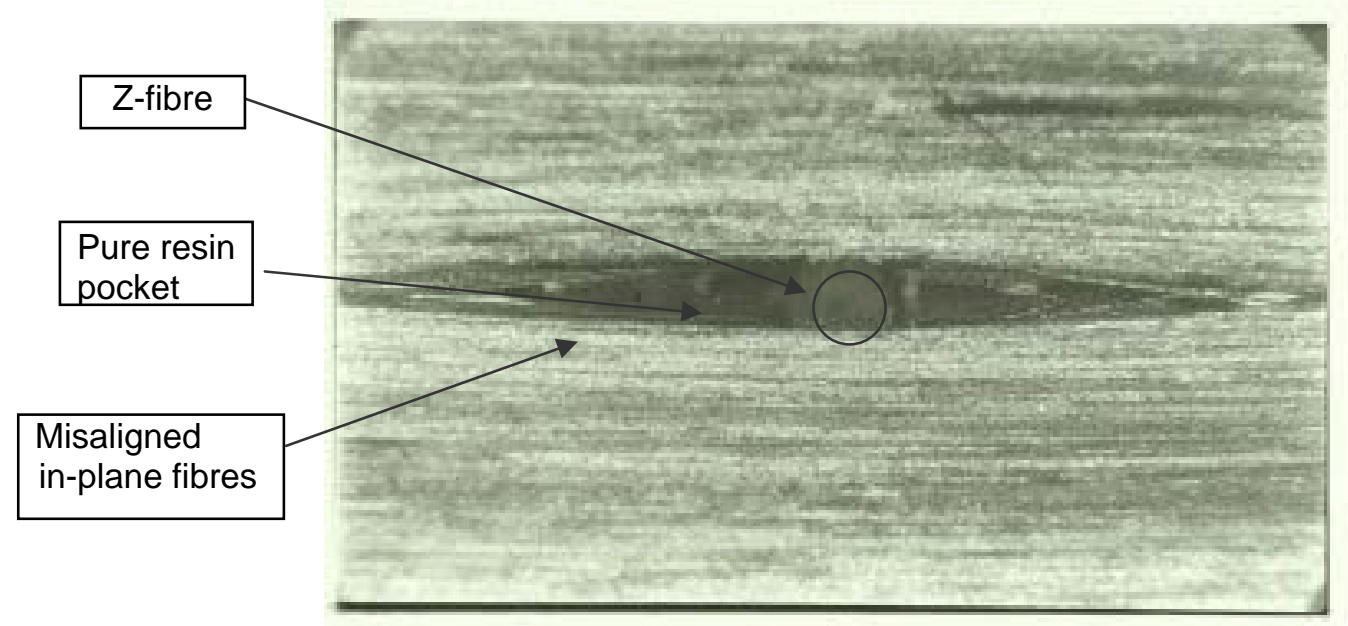

(a)
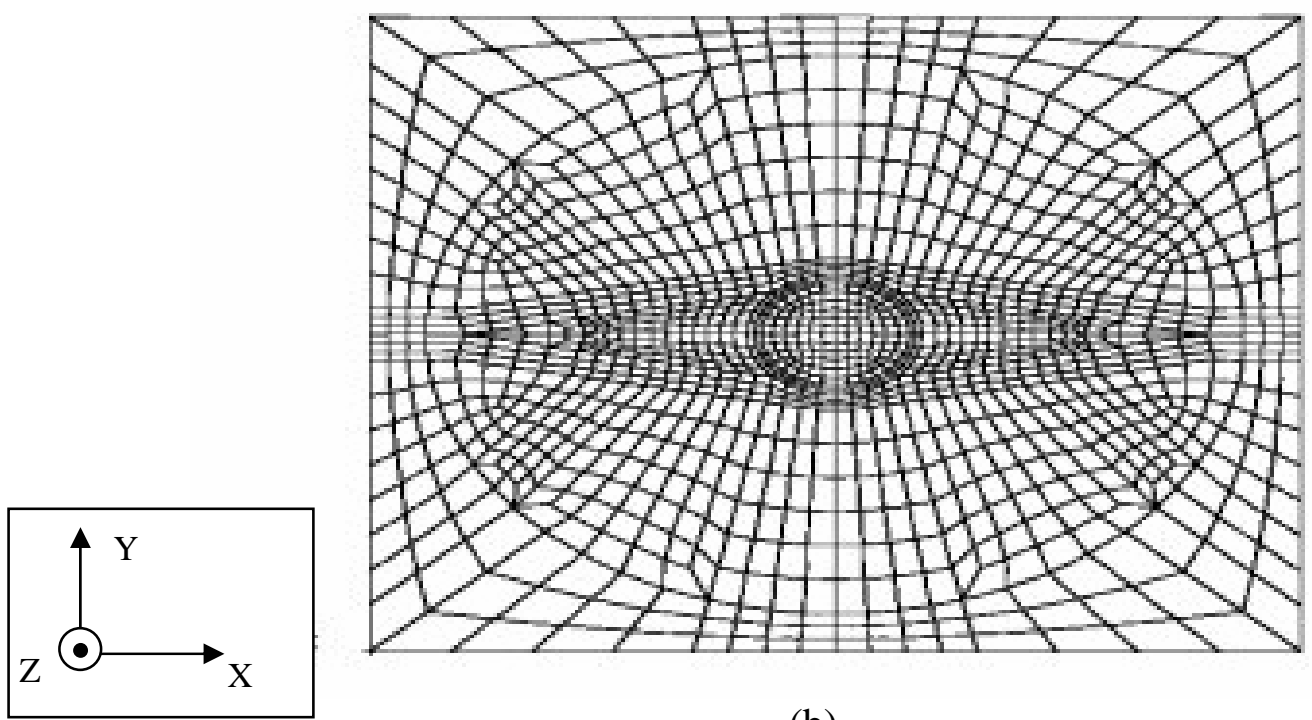

(b)

Fig. 1 (a) Microscopic photograph of a unidirectional laminate with a single z-fibre inserted;

(b) 3D finite element unit cell model (XY view) used in this study.

Table 1. Basic material properties used in the finite element models (unit: GPa).

\begin{tabular}{|c|c|c|c|c|c|c|c|c|c|c|}
\hline Materials & $\mathbf{E}_{\mathbf{1}}$ & $\mathbf{E}_{\mathbf{2}}$ & $\mathbf{E}_{\mathbf{3}}$ & $\mathbf{G}_{\mathbf{1 2}}$ & $\mathbf{G}_{\mathbf{2 3}}$ & $\mathbf{G}_{\mathbf{1 3}}$ & $\mathbf{v}_{\mathbf{1 2}}$ & $\mathbf{v}_{\mathbf{2 3}}$ & $\mathbf{v}_{\mathbf{1 3}}$ & $\mathbf{V}_{\mathbf{f}}$ \\
\hline $\begin{array}{c}\text { Lamina } \\
\text { (AS4/3501-6) }\end{array}$ & 136.40 & 8.90 & 8.90 & 5.95 & 3.21 & 5.94 & 0.25 & 0.38 & 0.25 & 0.6 \\
\hline $\begin{array}{c}\text { Z-fibre } \\
\text { (T300/9310) }\end{array}$ & 144.00 & 7.31 & 7.31 & 4.45 & 2.65 & 4.45 & 0.25 & 0.39 & 0.25 & \\
\hline $\begin{array}{c}\text { Epoxy Resin } \\
(3501-6)\end{array}$ & 4.44 & & & 1.65 & & & 0.34 & & & \\
\hline
\end{tabular}




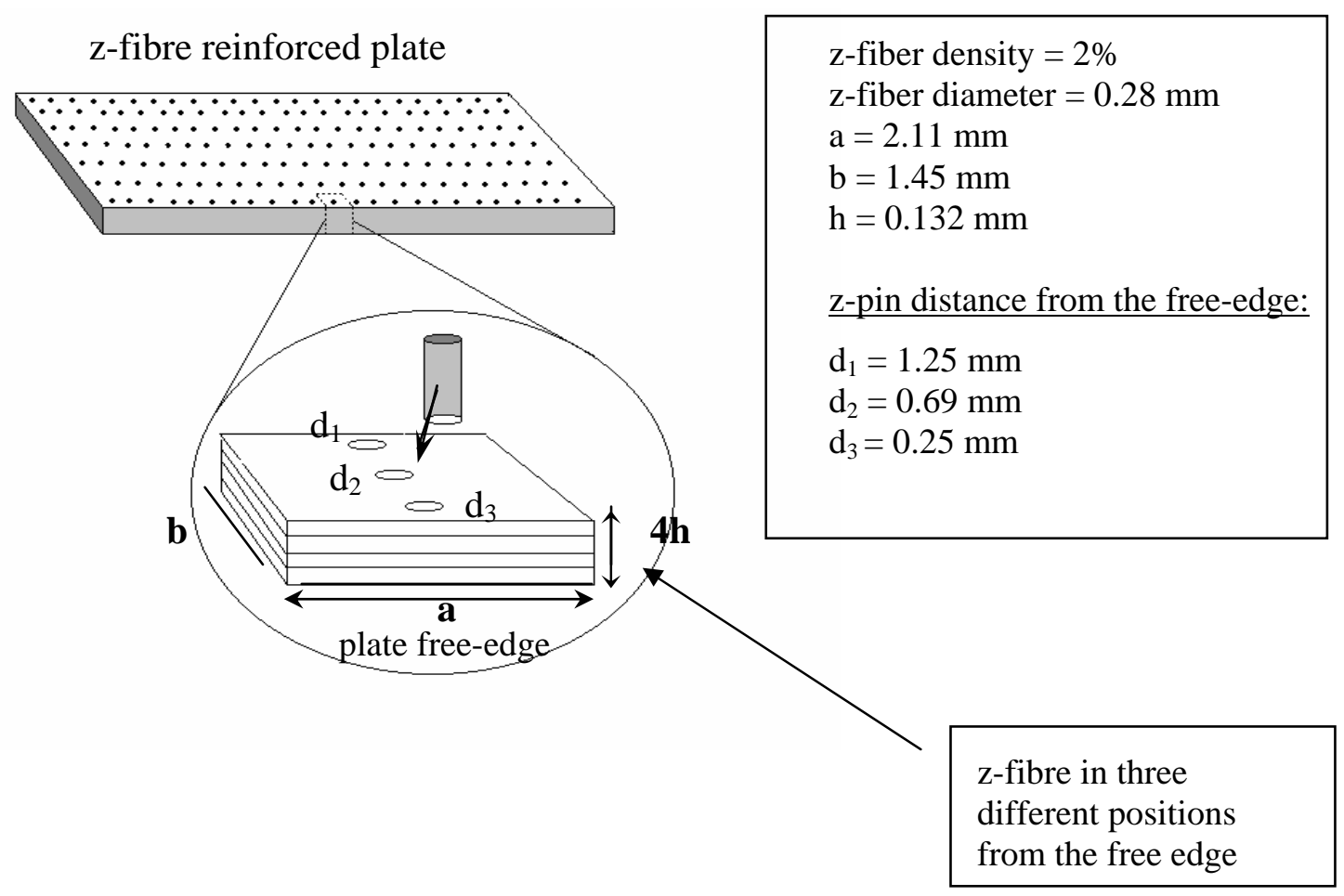

Fig. 2 (a) Schematic of a z-pin reinforced laminate with three different parametric distances from the freeedge.

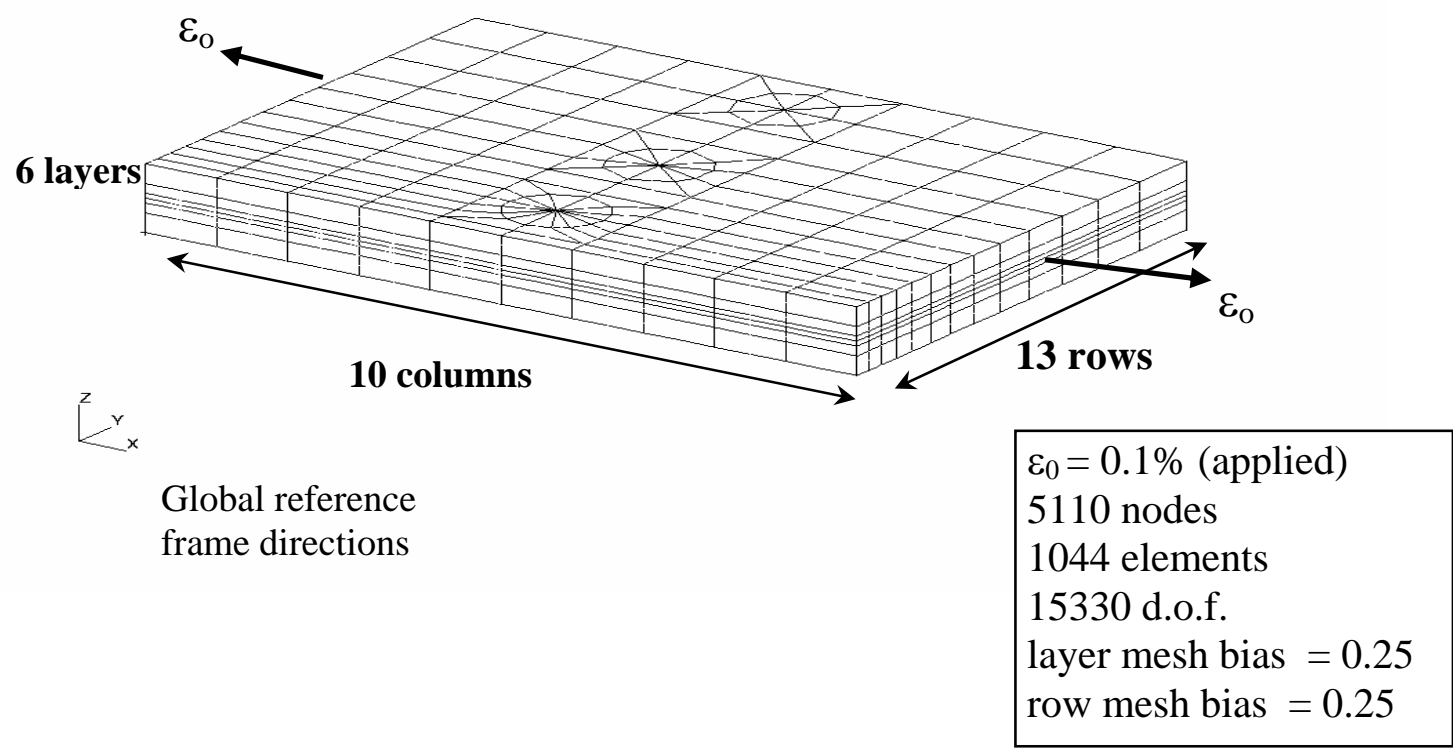

Fig. 2 (b) Finite element model of $1 / 4$ Z-pinned cross-ply laminate, [0, 90], under applied micro-strain $\varepsilon_{0}=0.1 \%$.

According to references [10-11], the engineering elastic constants of a heterogeneous composite can be described by equivalent engineering constants of a macroscopically homogeneous material. This could be done by averaging the micro-stresses and micro-strains ( $\sigma_{i j}$ and $\varepsilon_{i j}$ ) over the volume of the unit cell to yield the average macroscopic stresses and strains as given in equations (1) \& (2):

$$
\begin{aligned}
& \bar{\sigma}_{i j}=\frac{1}{V} \int_{V} \sigma_{i j}(x, y, z) d V \\
& \bar{\varepsilon}_{i j}=\frac{1}{V} \int_{V} \varepsilon_{i j}(x, y, z) d V
\end{aligned}
$$


The equivalence between the actual heterogeneous composite medium and the homogeneous medium described by the average stresses and strains and the equivalent elastic constants were demonstrated in [11]. The direct use of the above equations would be computationally expensive especially for models with a large numbers of degree of freedom. In order to avoid such problem the average strains could be found by applying the Gauss theorem that equates the stain energy between the volume of the unit cell and the boundary surface [11]:

$$
\overline{\varepsilon_{i j}}=\frac{1}{V} \int_{V} \varepsilon_{i j} d V=\frac{1}{2 V} \int\left(u_{i} n_{j}+u_{j} n_{i}\right) d S
$$

where, $V$ and $S$ are, respectively, the volume and the boundary surface of the unit cell, $u_{i}$ is the $i^{\text {th }}$ component of displacements and $n_{j}$ the $j^{\text {th }}$ component of the unit normal to $S$. The boundary displacements are determined by FEA.

The principle of strain energy equivalence between the external work and the stored deformation energy of the unit cell can be expressed as:

$$
\frac{1}{2} P_{i} \delta_{i}=\frac{1}{2} \overline{\sigma_{i j}} \bar{\varepsilon}_{i j} V
$$

Where $P_{i}$ is the external load applied on the unit cell, and $\delta_{i}$ is resultant displacement found by finite element analysis. From equations (3) \& (4) the average stress component acting on the unit cell is obtained as:

$$
\bar{\sigma}_{i j}=\frac{P_{i} \delta_{i}}{\bar{\varepsilon}_{i j} V}
$$

The effective elastic constants can then be found from the average stress and strain components. The boundary conditions and the external loads applied on the unit cell depend on the elastic constant required [11-12].

\subsection{Model for interlaminar stress analysis}

A 3-D model consisting of 20-noded hexahedral quadratic elements was used to model a z-pinned laminate. The micro-mechanical model represented a rectangular block of laminate containing one z-pin that might be placed in three different locations indicated as $d_{1}, d_{2}$, and $d_{3}$ with respect to the distance from z-pin to free edge as shown in Fig. 2(a). For meshing compatibility three z-fibre locations were allocated in the FE model but only one location was effectively assigned with the z-fibre material property whilst the other two had the properties of baseline laminate. FE model is shown in Fig. 2(b).
The z-fibre reinforced laminates analysed in this section were cross-ply $[0,90]_{s}$ and angle-ply $[ \pm 45]_{s}$ sequences. The z-fibres were arranged in a square array with a space of $2.11 \mathrm{~mm}$ representing a volume density of $2 \%$. The length for both models was $2.11 \mathrm{~mm}$; the width was 1.45 $\mathrm{mm}$ for the $[0,90]_{\mathrm{s}}$ laminate (522 20-noded hexahedronal solid elements, 3039 nodes) and 2.9 $\mathrm{mm}$ for the $[ \pm 45]_{\mathrm{s}}$ laminate where symmetric boundary condition cannot be applied (2088 20noded hexahedronal solid elements, 9489 nodes). This 3D FE model was used to examine the stress distribution near a $\mathrm{z}$-fibre and the interlaminar stress variation at the free edge. The distance between a z-pin and the free edge had a parametric variation from five times of a z-pin diameter (pin was placed far from the free-edge, at $d_{3}$ position) to one z-pin diameter (z-pin closest to the free edge, at $d_{1}$ position). The applied strain was $0.1 \%$ along the $x$-axis.

\section{Results and discussion}

\subsection{Comparison of elastic constants}

Tables 2 to 6 present calculated elastic constants and comparisons with some published results [13, 14] for various stacking sequences. As a baseline solution, Table 2 provides the elastic constants for the unpinned laminates. Tables $3,4,5$ \& 6 contain the elastic properties for the four different laminates, respectively; all had $2 \%$ volume density of z-fibres. In this numerical study it was assumed that $\mathrm{z}$-fibres were inserted at right angles $\left(90^{\circ}\right)$ to the principal in-plane axes, i.e. z-fibres are parallel to the $\mathrm{z}$-axis of the classical laminate theory. It should be noted that the closed form solution (CFS) [13] was originally formulated for a z-pinned sandwich panel with two laminate faceplates and a centre core. The elastic constants quoted in these tables for the CFS [13] were obtained by the authors of this paper by assuming a zero-thickness centre core. Therefore, two faceplates together with the correct laminate stacking sequence can be treated as a single laminate. The analytical CFS [13] only provided in-plane elastic properties. The comparisons show that the FE results obtained in this work agreed very well with both the closed form solution (CFS) [13] and the numerical unit cell solution [14]. Detailed comparisons for pinned and unpinned laminates based on this study are discussed below.

Firstly, for all four z-pinned laminates considered in this work, the through-thickness longitudinal modulus $E_{z}$ increased significantly, by $22-35 \%$, as 
shown in Fig. 3(a). The magnitude of increment depended on laminate stacking sequence. The Poisson's contraction ratio in the thickness direction was reduced because of the added zfibre stiffness.

Table 2. Stiffness values for control cases (unpinned). Unit of elastic modulus: GPa

\begin{tabular}{|l|c|c|c|c|c|c|c|c|c|}
\hline Lay-up & $\mathbf{E}_{\mathbf{x}}$ & $\mathbf{E}_{\mathrm{y}}$ & $\mathbf{E}_{\mathrm{z}}$ & $\mathbf{G}_{\mathrm{xy}}$ & $\mathbf{G}_{\mathrm{yz}}$ & $\mathbf{G}_{\mathrm{xz}}$ & $\mathbf{v}_{\mathrm{xy}}$ & $v_{\mathrm{yz}}$ & $v_{\mathrm{xz}}$ \\
\hline
\end{tabular}

Analytical Closed Form Solution [13]

\begin{tabular}{|c|c|c|c|c|c|c|c|c|c|}
\hline$[0,0]_{s}$ & 136.40 & 8.90 & 8.90 & 5.95 & 3.21 & 5.94 & 0.25 & 0.38 & 0.25 \\
\hline$[0,90]_{s}$ & 72.88 & 72.88 & /I & 5.95 & /I & // & 0.03 & /1 & // \\
\hline$[45,-45]_{s}$ & 20.57 & 20.57 & // & 35.36 & // & // & 0.73 & /1 & // \\
\hline$[45,0,-45,90]_{s}$ & 53.34 & 53.29 & // & 20.65 & /1 & // & 0.29 & // & // \\
\hline
\end{tabular}

Unit Cell Model [14]

\begin{tabular}{|l|c|c|c|c|c|c|c|c|c|}
\hline$[\mathbf{0 , 0}]_{\mathbf{s}}$ & 136.40 & 8.85 & 8.85 & 5.95 & 3.21 & 5.94 & 0.25 & 0.38 & 0.25 \\
\hline $\mathbf{[ 0 , 9 0 ] _ { \mathbf { s } }}$ & 72.80 & 72.80 & 10.05 & 5.90 & 4.16 & 4.16 & 0.03 & 0.36 & 0.36 \\
\hline $\mathbf{4 4 5 , - 4 5}]_{\mathbf{s}}$ & 20.52 & 20.52 & 10.05 & 35.30 & 4.25 & 4.25 & 0.73 & 0.10 & 0.10 \\
\hline $\mathbf{4 4 5 , 0 , - 4 5 , 9 0 ] _ { \mathbf { s } }}$ & 53.28 & 53.28 & 10.05 & 20.64 & 4.23 & 4.21 & 0.29 & 0.26 & 0.26 \\
\hline
\end{tabular}

Unit Cell Model (this study)

\begin{tabular}{|c|c|c|c|c|c|c|c|c|c|}
\hline$[0,0]_{s}$ & 136.40 & 8.86 & 8.81 & 5.95 & 3.20 & 5.94 & 0.25 & 0.37 & 0.25 \\
\hline$[0,90]_{\mathrm{s}}$ & 72.80 & 72.80 & 10.05 & 5.94 & 4.15 & 4.15 & 0.03 & 0.34 & 0.34 \\
\hline$[45,-45]_{\mathrm{s}}$ & 20.60 & 20.60 & 10.03 & 35.32 & 4.29 & 4.29 & 0.75 & 0.12 & 0.12 \\
\hline$[45,0,-45,90]_{s}$ & 53.28 & 53.28 & 10.05 & 20.64 & 4.21 & 4.23 & 0.29 & 0.26 & 0.26 \\
\hline
\end{tabular}

Table 3. Stiffness values for z-pinned UD laminate $[0]_{4}$ with $2 \%$ z-fibre density.

\begin{tabular}{|l|c|c|c|c|c|c|c|c|c|}
\hline & $\mathbf{E}_{\mathbf{x}}$ & $\mathbf{E}_{\mathbf{y}}$ & $\mathbf{E}_{\mathbf{z}}$ & $\mathbf{G}_{\mathbf{x y}}$ & $\mathbf{G}_{\mathbf{y z}}$ & $\mathbf{G}_{\mathbf{x z}}$ & $\mathbf{v}_{\mathbf{x y}}$ & $\mathbf{v}_{\mathbf{y z}}$ & $\mathbf{v}_{\mathbf{x z}}$ \\
\hline CFS [13] & 133.81 & 8.86 & 11.60 & 5.79 & 3.22 & 5.79 & 0.26 & 0.37 & 0.26 \\
\hline UC [14] & 123.10 & 8.85 & 11.17 & 5.80 & 3.17 & 5.70 & 0.31 & 0.31 & 0.20 \\
\hline UC (this study) & 121.80 & 8.60 & 11.92 & 5.81 & 3.13 & 5.67 & 0.33 & 0.27 & 0.24 \\
\hline
\end{tabular}

Table 4. Stiffness values for $\mathrm{z}$-pinned cross-ply [0, 90]s with $2 \% \mathrm{z}$-fibre density.

\begin{tabular}{|l|c|c|c|c|c|c|c|c|c|}
\hline & $\mathbf{E}_{\mathbf{x}}$ & $\mathbf{E}_{\mathbf{y}}$ & $\mathbf{E}_{\mathbf{z}}$ & $\mathbf{G}_{\mathbf{x y}}$ & $\mathbf{G}_{\mathbf{y z}}$ & $\mathbf{G}_{\mathbf{x z}}$ & $\mathbf{v}_{\mathbf{x y}}$ & $\mathbf{v}_{\mathbf{y z}}$ & $\mathbf{v}_{\mathbf{x z}}$ \\
\hline CFS [13] & 71.50 & 71.50 & $/ /$ & 5.80 & $/ /$ & $/ /$ & 0.032 & $/ /$ & $/ /$ \\
\hline UC [14] & 67.48 & 67.48 & 12.30 & 5.87 & 4.00 & 4.00 & 0.04 & 0.29 & 0.29 \\
\hline UC (this study) & 67.30 & 67.30 & 12.31 & 5.82 & 3.98 & 3.98 & 0.05 & 0.30 & 0.30 \\
\hline
\end{tabular}

Table 5. Stiffness values for z-pinned angle-ply [45, -45$] \mathrm{s}$ with $2 \%$ z-fibre density. 


\begin{tabular}{|l|c|c|c|c|c|c|c|c|c|}
\hline & $\mathbf{E}_{\mathbf{x}}$ & $\mathbf{E}_{\mathbf{y}}$ & $\mathbf{E}_{\mathbf{z}}$ & $\mathbf{G}_{\mathbf{x y}}$ & $\mathbf{G}_{\mathbf{y z}}$ & $\mathbf{G}_{\mathbf{x z}}$ & $v_{\mathbf{x y}}$ & $v_{\mathbf{y z}}$ & $\mathbf{v}_{\mathbf{x z}}$ \\
\hline CFS [13] & 20.09 & 20.09 & $/ /$ & 34.69 & $/ /$ & $/ /$ & 0.72 & $/ /$ & $/ /$ \\
\hline UC [14] & 20.10 & 20.10 & 12.37 & 32.00 & 4.13 & 4.13 & 0.71 & 0.09 & 0.09 \\
\hline UC (this study) & 19.45 & 19.45 & 12.27 & 31.90 & 4.10 & 4.10 & 0.70 & 0.10 & 0.10 \\
\hline
\end{tabular}

Table 6. Stiffness values for $\mathrm{z}$-pinned laminate $[+45,0,-45,90]_{s}$ with $2 \%$ z-fibre density.

\begin{tabular}{|l|c|c|c|c|c|c|c|c|c|}
\hline & $\mathbf{E}_{\mathbf{x}}$ & $\mathbf{E}_{\mathbf{y}}$ & $\mathbf{E}_{\mathbf{z}}$ & $\mathbf{G}_{\mathbf{x y}}$ & $\mathbf{G}_{\mathbf{y z}}$ & $\mathbf{G}_{\mathbf{x z}}$ & $\mathbf{v}_{\mathbf{x y}}$ & $\mathbf{v}_{\mathbf{y z}}$ & $v_{\mathbf{x z}}$ \\
\hline CFS [13] & 52.35 & 52.35 & $/ /$ & 20.25 & $/ /$ & $/ /$ & 0.28 & $/ /$ & $/ /$ \\
\hline UC [14] & 49.70 & 49.70 & 12.30 & 19.00 & 4.09 & 4.09 & 0.30 & 0.21 & 0.21 \\
\hline UC (this study) & 49.51 & 49.51 & 12.00 & 18.87 & 3.98 & 3.98 & 0.29 & 0.19 & 0.19 \\
\hline
\end{tabular}
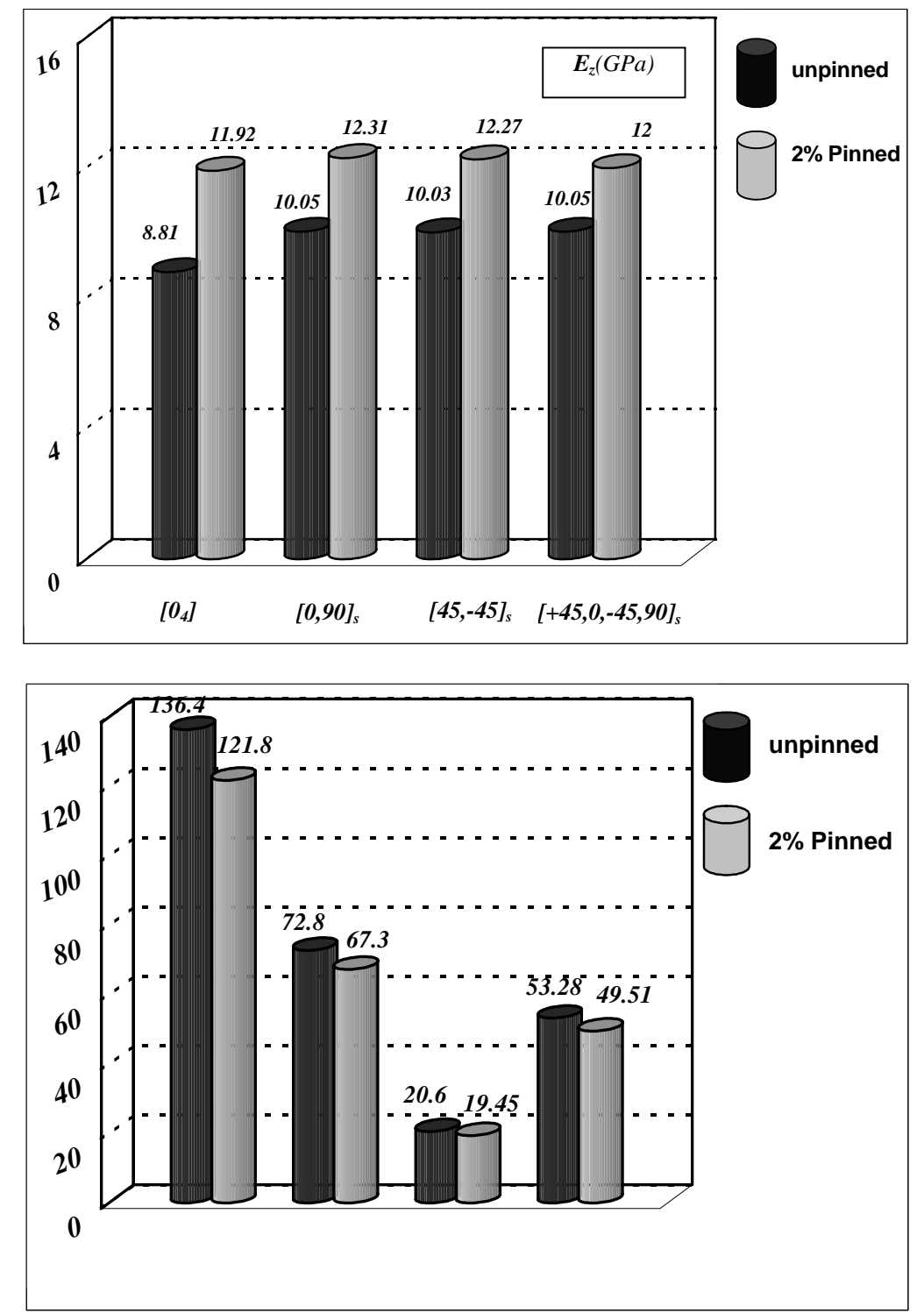

Fig. 3 Stiffness variations for four different laminates: (a) through-thickness longitudinal modulus $E_{z}$; (b) in-plane longitudinal modulus $E_{x}$. 
For the in-plane elastic properties, all stacking sequences showed a small reduction in the Young's moduli that were contained within $10 \%$. Examples for the longitudinal modulus $E_{x}$ are shown in Fig. 3(b). The worst case was $E_{x}$ of the UD laminate $[0]_{4}$. This can be attributed to the influence of misaligned in-plane fibres and pure resin region caused by insertion of z-fibres; the deviated inplane fibres along the longitudinal direction and the pure resin zone would make the longitudinal stiffness and strength weaker. For the $[0,90]_{\mathrm{s}}$ laminate the reductions in moduli $E_{x}$ or $E_{y}$ were about $7 \%$. The reduction in the shear modulus $G_{x y}$ for the $[0]_{4}$ and $[0,90]_{s}$ laminates was less significant compared to the reduction in the Young's modulus because the angled fibre region around a z-pin can carry more shear load and thus provides extra stiffness that offsets the added compliance due to the pure resin region. The local shear stresses carried by the deviated fibres can be seen in Fig. 4. For the $[ \pm 45]_{s}$ laminate $G_{x y}$ was reduced by $9 \%$, whilst for the quasi-isotropic laminate a smoothed almost uniform reduction in $E_{x}, E_{y}$ and $G_{x y}$ was observed (6-7\%).

The computational results demonstrated that the in-plane fibre alignment is a critical factor for the in-plane stiffness values of z-pinned composites. From this point of view, z-pin diameters should be minimised in order to minimise the angle of misaligned in-plane fibres and to avoid microbuckling during compressive loads.
The CFS [13] appeared to have predicted some of the elastic constants quite well. The model was based on the volume fraction of $\mathrm{z}$-fibres using the simple rule of mixture for the laminate properties and the classic laminate theory. Since the z-fibre volume fraction plays a crucial role in some elastic properties, such as the transverse and shear moduli, the CFS was accurate enough for these constants. However, larger differences resulted between the CFS and FE solutions in the in-plane longitudinal modulus, $E_{x}$, as shown in Fig. 3(b) and Tables 3, 4, and 6. In these cases, the CFS overestimated the values of $E_{x}$ for the UD and cross-ply laminates, and $G_{x y}$ for the angle-ply laminate. This is because that the closed-form analysis did not consider the effect of the misaligned in-plane fibres and resin pocket around a z-pin, which do weaken the stiffness and strength in the longitudinal direction. However, the overall results obtained from the CFS [13] were accurate enough. The disagreement with the two FE results was contained within $5-7 \%$ as shown in Tables 3-6. The CFS model is easy to use for quick estimation of the stiffness properties for this new composite material.

It's worth mentioning that the FE results of this study were also validated against the experimental data provided in [4]. The tests were conducted with a different carbon fibre material using also $2 \%$ volume fraction of $z$-fibres. The same range of variations in the elastic constants as aforementioned examples was found.

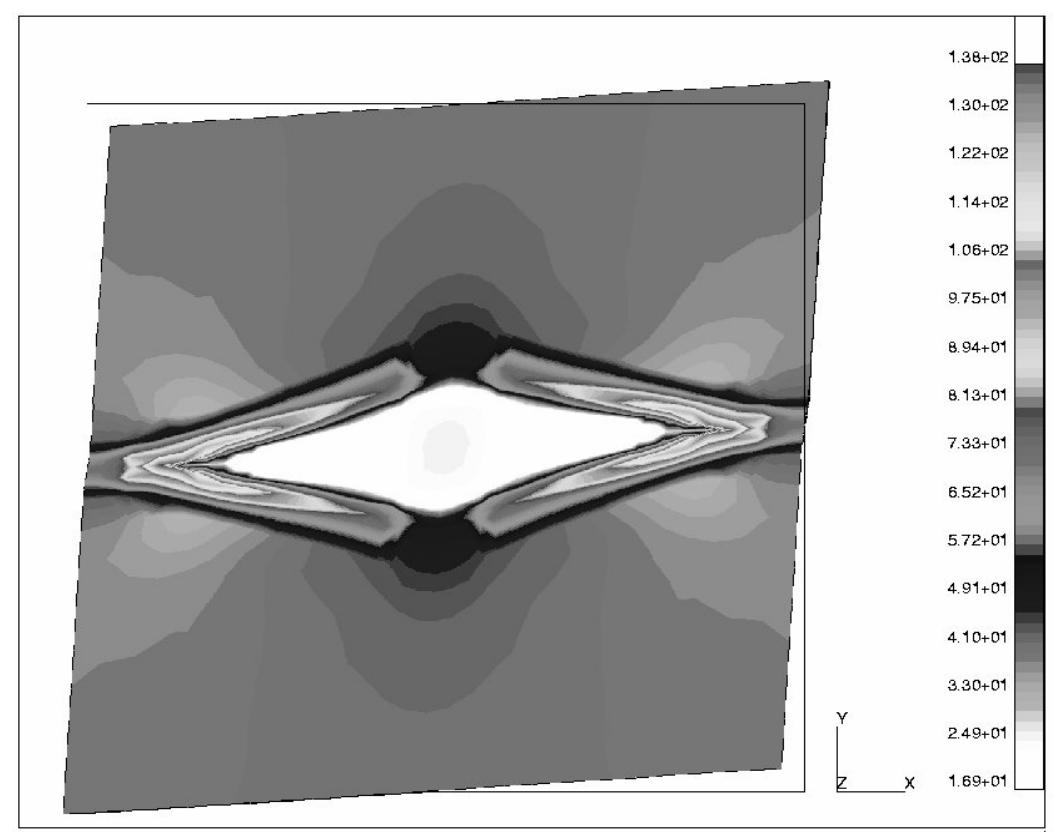

Fig. 4 In-plane shear stress distribution around a z-fibre (UD laminate). Note: deviated in-plane fibre region carried shear stresses providing extra stiffness that offset the added compliance due to the pure resin region. Unit: MPa.

3.2 Stress field around a z-fibre 
The stress field in a z-fibre inclusion is essentially three-dimensional under uniaxial loads. This can be demonstrated by the following example. A uniform strain of $0.1 \%$ was applied in the $x$-axis of a unidirectional laminate. It resulted in an increased shear path along the misaligned fibre region as well as interlaminar stress components. This was due to the excessive mismatch of the elastic properties between the $z$-fibre and the surrounding laminate region. The von Mises stress is plotted in Fig. 5 showing high stress concentration around the z-pin. The figure also shows that the stress perturbation due to the zpin's presence disappeared beyond a distance of about two z-fibre diameters from the axis line of the z-pin. Therefore, z-fibre spacing and its interaction with the resin-rich zone should be further studied.
The FE results also showed that when carrying the through-thickness stress components z-fibres absorbed up to $25 \%$ of the total elastic strain deformation energy stored in the unit cell; a nonuniform shear lag at the interface of the z-fibre and matrix was observed from the numerical example. Therefore material compatibility and the interfacial adhesive bond between the z-fibres and their surrounding matrix are important because a large part of the through-thickness loads is transferred to the $z$-fibres. This was also mentioned in several papers based on experimental investigations, e.g. ref [18]. From this point of view, for carbon/epoxy laminates a carbon z-pin would be a better choice, which offers excellent adhesion to the surrounding thermo-set resin and good compatibility characteristics.
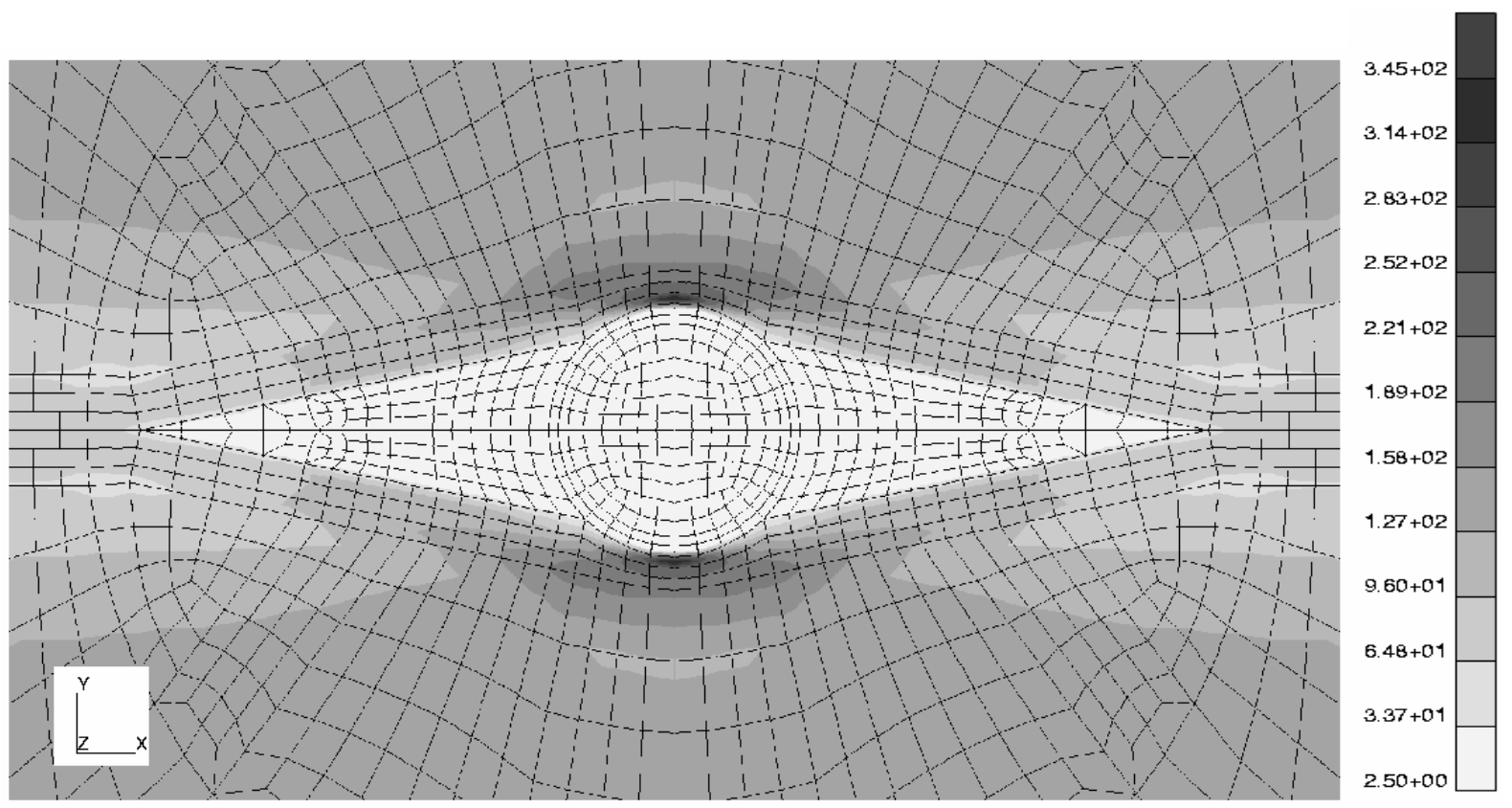

Fig. 5 Von Mises stress field around a z-fibre (UD laminate). Applied strain $\varepsilon_{0}=0.1 \%$. Stress unit: MPa.

\subsection{Interlaminar stresses}

At the laminate free edge, the interlaminar stresses are extremely high. According to the classic lamination theory, the interlaminar normal stress (or peeling stress) for the [0/90] cross-ply laminate goes to infinity at the free edge. This is a stress singularity problem. The distance over which the free-edge interlaminar stresses rise shapely is very small. According to the study by Hu \& Soutis [15] this characteristic distance had a maximum length of 2-ply thickness. Therefore, for carbon/epoxy composite this distance is about
$0.25 \mathrm{~mm}$. In order to study the effect of z-pinning on interlaminar stresses, z-pins were placed at three parametric distances, i.e. $d_{1}, d_{2}$ and $d_{3}$, being $1.25,0.69$ and $0.25 \mathrm{~mm}$ from the free edge respectively as shown in Fig. 2. It was expected that only the z-fibre position at $d=d_{3}$ could give relevant results with regard to stress singularity. Two laminate stacking sequences were studied in the present work. They were $[0 / 90]_{\mathrm{s}}$ and $[ \pm 45]_{\mathrm{s}}$ laminates. 


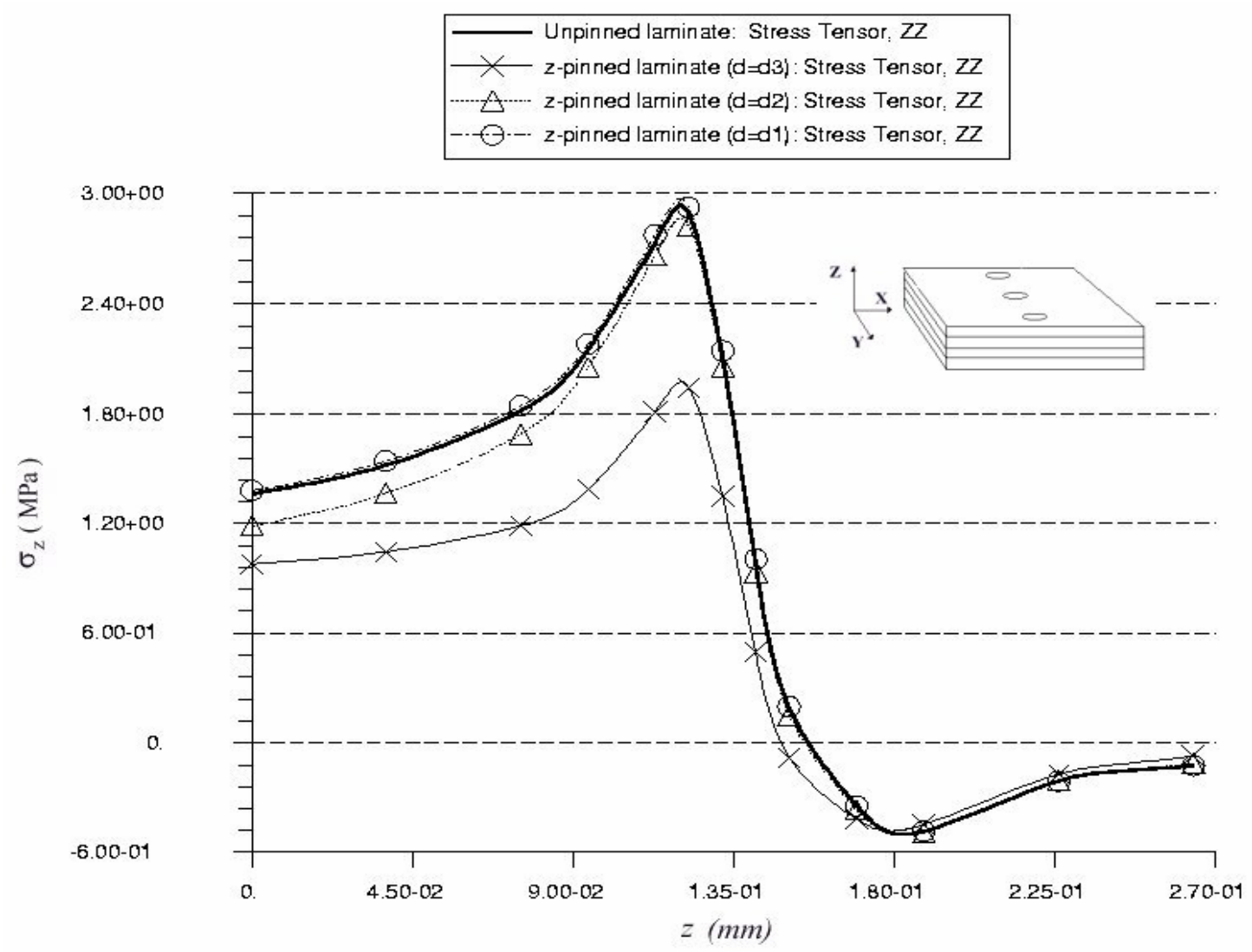

(a)

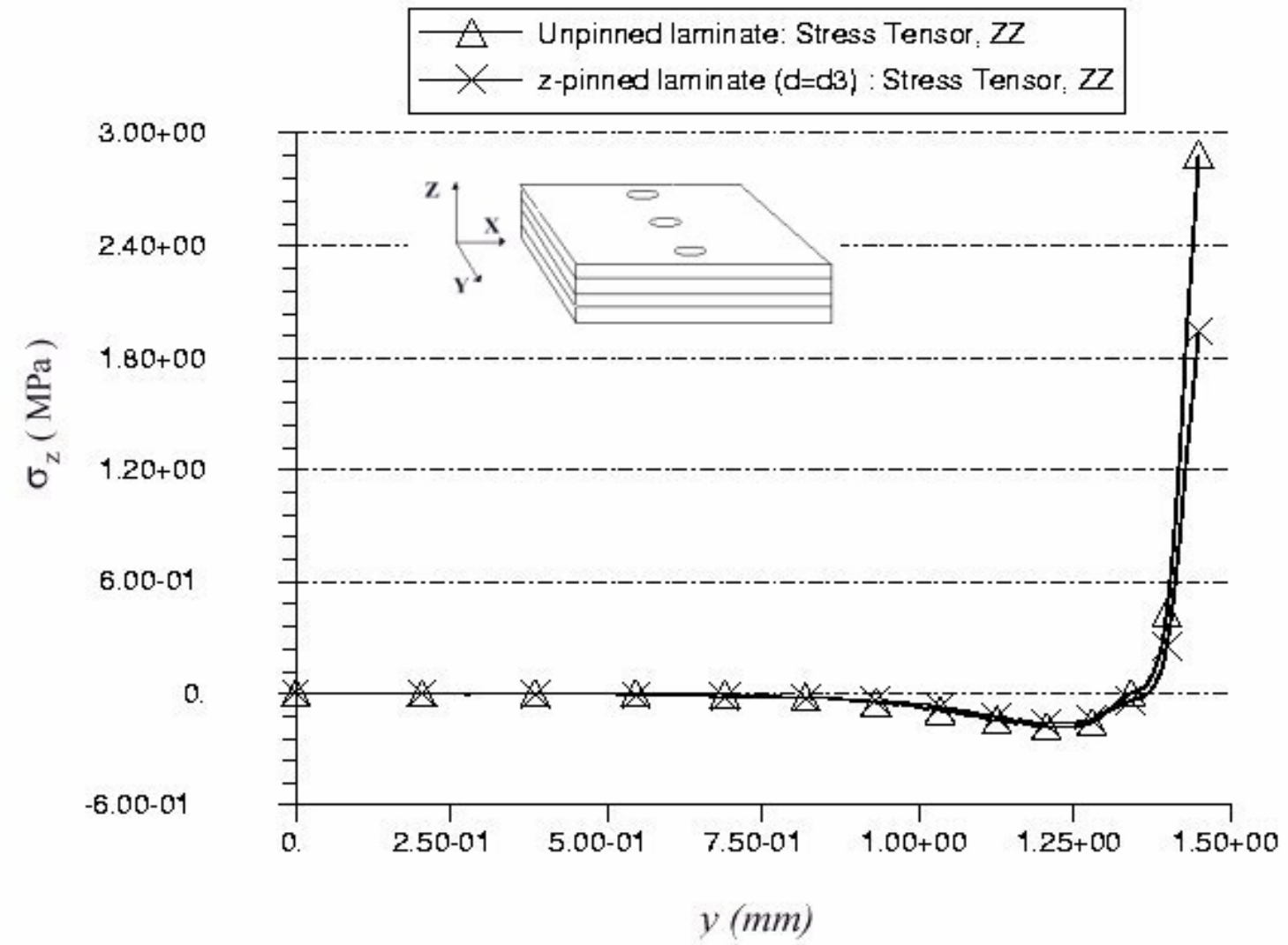

(b) 


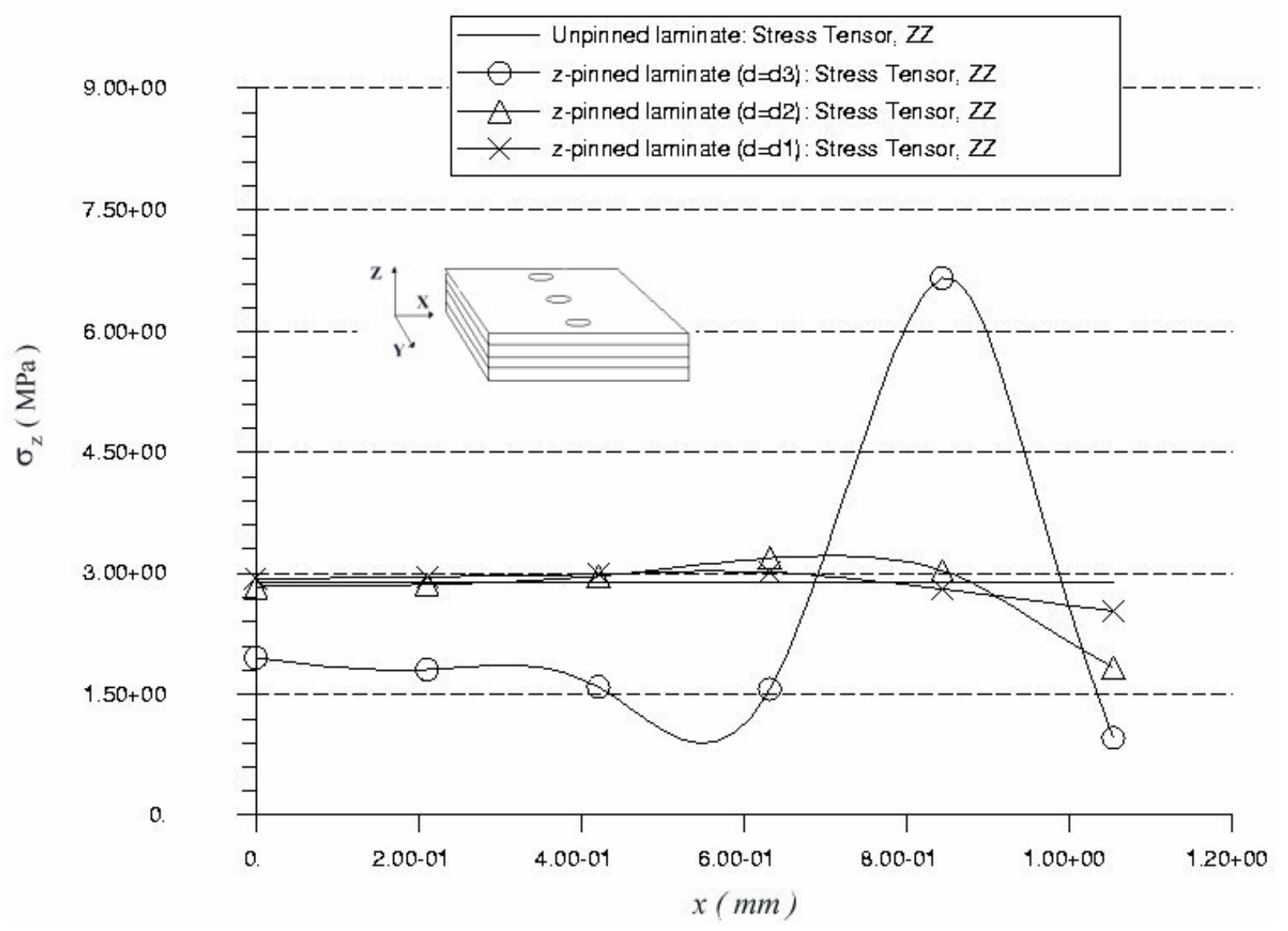

(c)

Fig. $6 \mathrm{FE}$ results of $\sigma_{\mathrm{z}}$ stress distributions for [0, 90 $]_{\mathrm{s}}$ cross-ply laminate: (a) through-the-thickness variation (along $z$-axis); (b) from inside plate to the free edge ( $y$-axis); (c) along the free-edge (x-axis).

Since the $[0,90]_{s}$ laminate exhibits only a Poisson mismatch between the layers (no shear coupling), stress components $\sigma_{\mathrm{z}}$ and $\tau_{\mathrm{yz}}$ are the non-zero interlaminar stresses. Fig. 6 shows the distributions of the interlaminar normal stress, $\sigma_{\mathrm{z}}$, along the three principal axes and for both pinned and unpinned laminates. Figs. 6(a) \& (b) show that the maximum interlaminar peeling stress was reduced significantly at the free edge when a zpin are placed at the immediate vicinity of the free edge, i.e. $d=d_{3}$. The peak stresses for the pin distances $d_{1}$ and $d_{2}$ had virtually the same values as those of unpinned laminate. However, when the peeling stress in the localised laminate was reduced by placing a z-pin at $d=d_{3}$, the z-pin itself picked up these high free-edge stresses, as shown in Fig. 6(c), in order to satisfy the equilibrium conditions. Similar stress distributions were found for the interlaminar shear stress component $\tau_{\mathrm{yz}}$. Therefore, in the stress concentration regions zfibres resist interlaminar stresses if they are placed in the close vicinity of the stress raiser.
Since the interface between a z-fibre pin and the surrounding resin pool is relatively weak, delamination damage is still likely to initiate from this free edge region.

The $[ \pm 45]_{s}$ angle-ply laminate exhibits only shear coupling (no Poisson mismatch between layers), so $\tau_{\mathrm{xz}}$ is the only non-zero interlaminar stress. The interlaminar shear stress has its maximum value at the mid-thickness and reduces to zero on the outside of the laminate. Figs. 7(a) \& (b) plot through-the-thickness distributions of $\tau_{\mathrm{xz}}$ showing that z-pinning can reduce the maximum shear in the mid-thickness by about $15 \%$ if a pin was placed at $d=d_{3}$. The stress values for pin distances $d_{1}$ and $d_{2}$ were virtually the same as those of unpinned laminate. Part of the through-thickness stress was carried by the z-fibre placed at $d=d_{3}$, as shown in Fig. 7(c). The differences in the legends in Figures 6 and 7 should be noted.

The above stress analysis showed that interlaminar stress components could be reduced only when $\mathrm{z}$ - fibres were placed in the immediate vicinity to the free edge (within $0.25 \mathrm{~mm}$ ). 


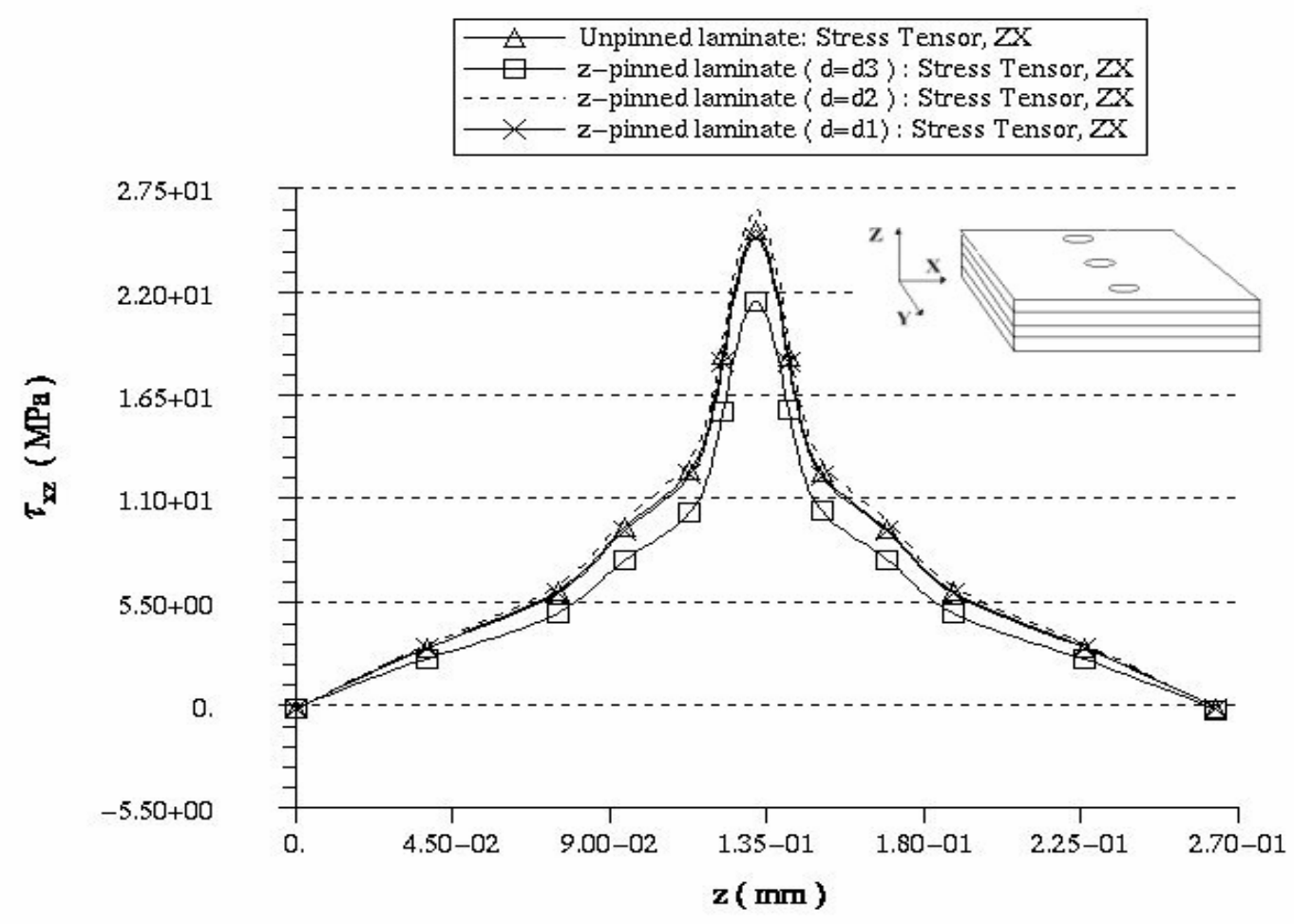

(a)

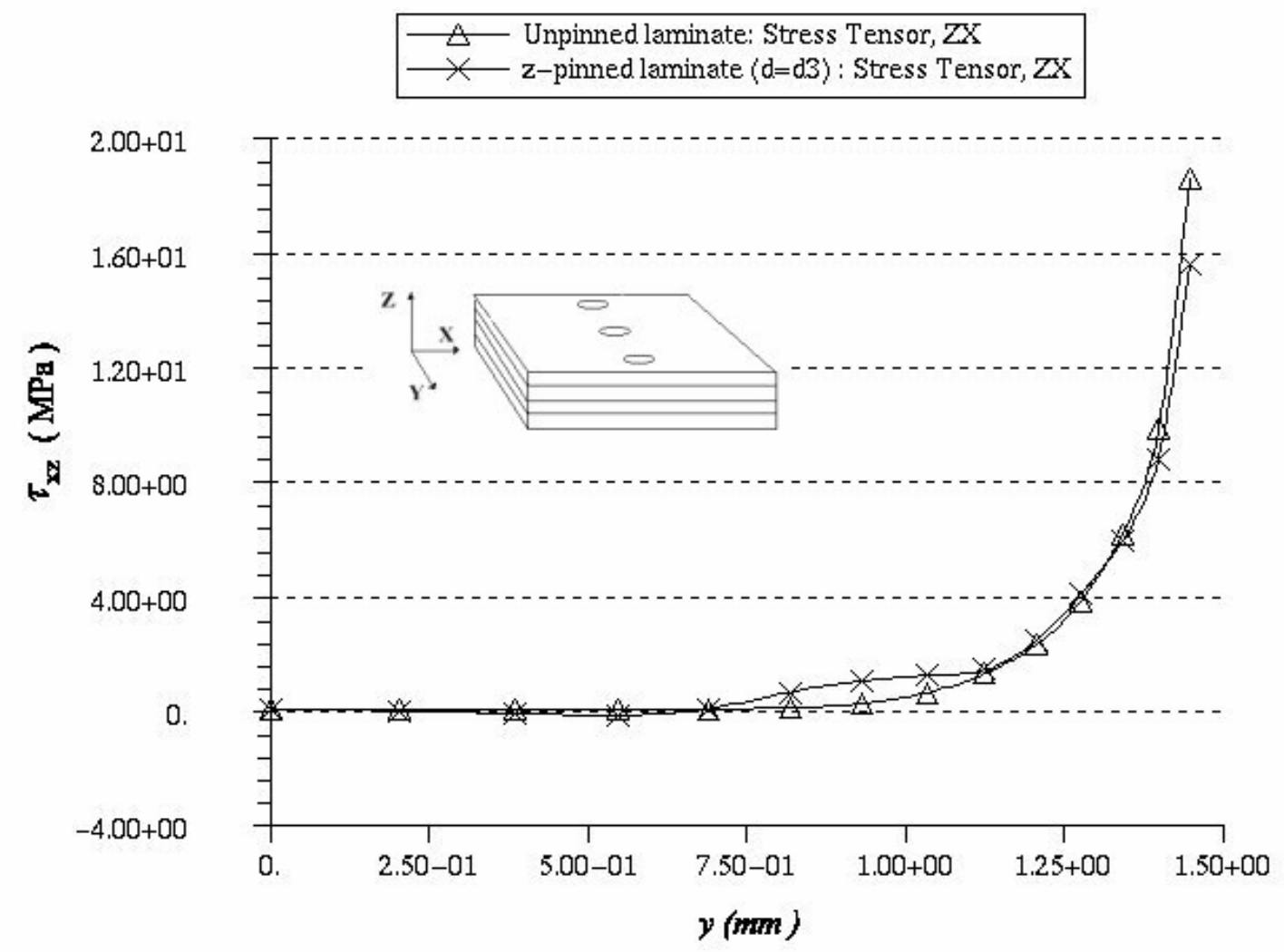

(b) 


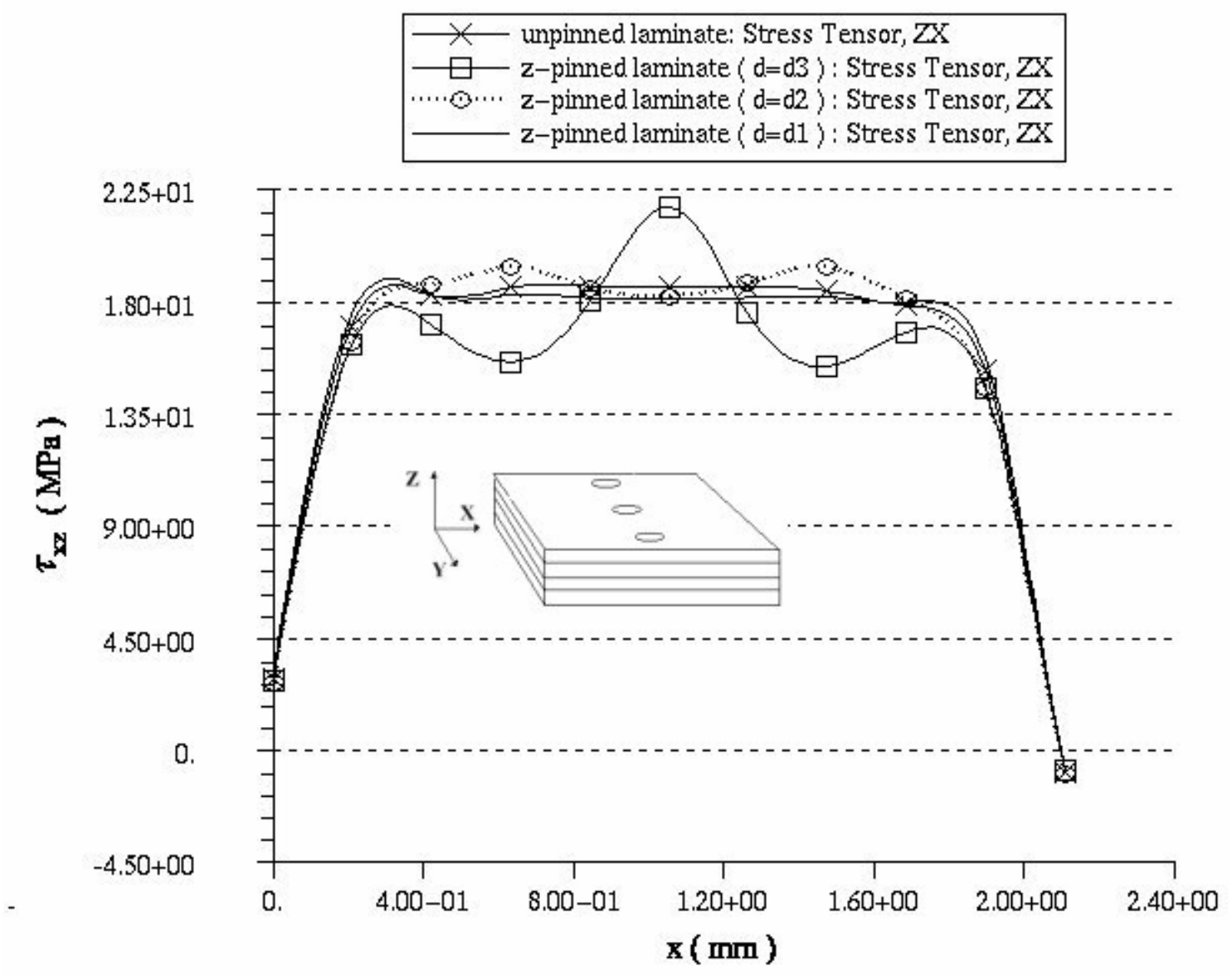

(c)

Fig. $7 \mathrm{FE}$ results of $\tau_{x z}$ stress distribution for [45, -45] $]_{\mathrm{s}}$ angle-ply laminate: (a) through-the-thickness variation (along $z$-axis); (b) from inside plate to the free-edge ( $y$-axis); (c) along the free-edge ( $x$ axis).

Even though the stress distributions were significantly affected, there were no overall reductions in these peak stresses in the region since the z-pins picked up some high stresses. Barrett [16] obtained similar results for a different stress singularity problem, i.e. an interlaminar crack in z-pinned laminate under Mode I loading. It should be noticed that over such a small distance the assumption of material homogeneity for the laminates might break down and the bimaterial nature of the composite should be taken into account. Further work is necessary for more detailed stress analysis using micro-mechanical models for the surrounding matrices.

\section{CONCLUSIONS}

Three-dimensional micro-mechanical finite element models were employed to examine the mechanical behaviour of z-pinned laminates. Tasks performed were: (a) calculation of the engineering elastic constants, and (b) study of stress distribution around a $\mathrm{z}$-fibre and at $\mathrm{z}$ pinned laminate free edges. Following main conclusions may be drawn.

By adding two percent volume fraction of z-fibres the through-thickness Young's modulus $\left(E_{z}\right)$ was increased significantly, i.e. by $22-35 \%$, for the four different laminates studied in this work. The reductions in the in-plane moduli were contained within $7-10 \%$. Therefore, the $\mathrm{z}$-fibre technique is very effective for design against damages caused by out-of-plane loads, e.g. impact and stiffeners pull-off.

The interlaminar stress distributions near the free edge of a z-pinned laminate were significantly affected when $\mathrm{z}$-fibres were placed within a characteristic distance of one $\mathrm{z}$-fibre diameter from the free-edge. Detailed numerical analysis showed that local z-fibres carried significant amount of the interlaminar normal and shear 
stresses. Therefore, z-pins may be used to reinforce free edges around structural cut-outs Acknowledgement

The work reported here was funded by the DTI CARAD programme, via the MERCURYM project. The authors would also like to acknowledge Dr I Partridge, Dr. D Cartie and M Troulis for helpful discussions.

\section{References}

1. Freitas G, Fusco T, Campbell T, Harris J \& Rosenberg S. Z-Fiber ${ }^{\mathrm{TM}}$ Technology and Products for Enhancing Composite Design. Proc of $83^{\text {rd }}$ Meeting of the AGARD SMP, 1996, CP-590.

2. Freitas G, Fusco T, Magee C \& Dardzinski P. Fibre insertion process for improved damage tolerance in aircraft structures. $J$. of Advanced materials, $2 \mathbf{5}$ (1994).

3. Cartie DDR \& Partridge IK. Z-pinned composite laminates: improvements in delamination resistance. Proc $5^{\text {th }}$ Int Conf on Deformation and Fracture of Composites, 1999.

4. Preliminary lamina, laminate and sub-element test results for Z-fiber ${ }^{\mathrm{TM}}$ reinforced IM7/9773 uni-directional tape and fabric. AZTEX, Version 1.3 - 1998.

5. Bitsianis N. The influence of z-pinning on toughness and impact performance of carbon fibre polymer composite materials. $M S C$ Thesis, Cranfield University, 1999.

6. Palazotto AN, Gummadi LNB, Vaidya UK, Herup EJ. Low velocity impact damage characteristics of Z-fibre reinforced sandwich panels - an experimental study. Composite Structures, 43(1999), 275-288.

7. Farley GL \& Dickinson LC. Mechanical response of composite materials with through-the-thickness reinforcement. NASA CR-14753, 1993, 123-143.

8. Childress JJ and Freitas G. Z-direction pinning of composite laminates for increased survivability. Proc of the AIAA Aerospace Design Conference, 1992, 1092-1099.

9. Altergott W. The Z-Fiber process, throughthickness reinforcement for composite and to reinforce structural interface of co-cured components such as stiffeners flanges. structures. Proc of the 10th DOD/NASA/FAA Conf of Fibrous Composites in Structural design, NAWCADWAR-94096-60, 1994, pp.71-93.

10. Sun CT \& Li S. Three-dimensional effective elastic constants for thick laminates. Journal of Composite Materials. 1988. Vol. 22, 629639.

11. Sun CT \& Vaidya RS. Prediction of composites properties from a representative volume element. Composite Sci \& Tech. 1996, Vol. 56, 171-179.

12. Whitcomb JD, Chapman CL \& Tang X. Derivation of boundary conditions for micromechanics analyses of plain and satin weave composites. J Comp Mat. 34(2000), 724-747.

13. Lin CJ \& Chan WS. Stiffness of composite laminates with z-fibre reinforcement. Proc AIAA/ASME/ASCE/AHS/ASC Structures, Structural Dynamics, \& Materials Conference, St. Louis MO, April 1999. Paper No. AIAA-99-1294, 918-924

14. Dickinson LC, Farley GL, \& Hinders MK. Prediction of effective three-dimensional elastic constants of translaminar reinforced composites. J of Composite Materials. $\underline{33}$ (1999), 1002-1029.

15. Hu FZ \& Soutis C. Interlaminar stresses in composite laminates with a circular hole. Composite Structures. 37 (1997), 223-232.

16. Barrett DJ. The mechanics of z-fibre reinforcement. Composite Struts, 36 (1996), 23-32.

17. Craig A \& Fleck NA. Z-pinned composite laminates: knockdown in compressive strength. 5th Int Conf on Deformation and Fracture of Composites, 1999, 60-68.

18. Troulis M, Cartie DDR, L Barattoni \& Partridge IK. Z-pinned woven laminates: interlaminar fracture results and pinned quality considerations. Proc. Int Conf. On Deformation \& Fracture of Composites (DFC 6), Manchester, April 2000.

Published in Composites Part A: applied science and manufacturing, Vol. 33 (2002), 16531664. Publisher: Elsevier. 